\title{
Expectations, Learning and the Costs of Disinflation Experiments using the FRB/US Model
}

\author{
Antúlio Bomfim, Robert Tetlow, Peter von zur Muehlen and John Williams* \\ Board of Governors of the Federal Reserve System \\ Washington, DC 20551
}

August 21, 1997

\begin{abstract}
The macroeconomic costs of disinflation are considered for the United States in a rational expectations macroeconometric model with sticky prices and imperfect information regarding monetary policy objectives. The analysis centers on simulation experiments using the Board's new quarterly macroeconometric model, FRB/US, within which are nested both expectations formation that is 'rational' (i.e., model consistent) and 'restricted-information rational' (i.e., where the information set is restricted to that captured by a small-scale VAR model). We characterize monetary policy as being governed by rules. Disinflations are represented by changes in the target inflation rate of a interest-rate reaction function. Two kinds of rules are considered: a version of the Taylor rule and the other being a more aggressive and richer specification estimated using data for the last 15 years. We assume agents are not fully cognizant of changes in the Fed's inflation target and must instead adjust their perceptions of the target according to a linear updating rule. Simulation results for sacrifice ratios are compared with results from other models and with econometric results and calculations reported in the literature.

\footnotetext{
* Corresponding author: R. Tetlow at e-mail address: m1rjt99@ frb.gov or snail mail to Stop 61-A. This is a revised version of a paper presented at the BIS meeting of model builders, January $16 \& 17,1997$, in Basle, Switzerland. The views expressed in this article are those of the authors and are not necessarily those the Board of Governors of the Federal Reserve System or its staff. The authors thank, without implication, Palle Andersen, Flint Brayton, Dave Reifshneider and G. Sutton for helpful remarks and Steve Sumner for able research assistance.
} 


\section{Introduction}

In the first quarter of 1980, quarterly inflation in the United States reached over 16 per cent, and over the ten years ending in 1982Q4, the average rate of inflation rate was 8.8 per cent. ${ }^{1}$ The outbreak of inflation in the 1970s in the United States and elsewhere engendered a greater concern among central bankers worldwide of the cost of inflation, and with it, the employment costs of disinflation. Over the period from 1983Q1 to 1996Q3 -- that is, after the Volcker disinflation -- U.S. inflation averaged 3.5 per cent.

In many respects, the Volcker disinflation was unique in the American experience. It coincided with changes in Fed operating procedures, most notably in the adoption of monetary targeting. The disinflation also commenced from a point at or near a local maximum in the inflation rate. Perhaps more importantly, the ex post sacrifice ratio of one is relatively low by historical standards. ${ }^{2}$ According to Ball (1994), the sacrifice ratio for this episode was about one; that is, it required the equivalent of a one-percentage-point decrease in the employment rate for one year for each percentage point reduction of inflation. ${ }^{3}$ Table 1 documents much of the history of disinflations in the U.S. and shows the Volcker disinflation as the least costly in recent history. The most notable features of Table 1 are, first, that disinflations have always been costly in terms of foregone employment, and, second, that the cost has varied significantly over episodes and depends on the method of measurement.

These observations raise the issue of whether the way in which a disinflation is carried out significantly affects the costs that must be borne along the transition path. More generally, the question for policy makers is 'what are the sources of costly inflation adjustment and is there a way in which monetary policy can affect these costs?'

1. Inflation, in this context, means the rate of change from a year earlier of the quarterly consumer price index, (all items, all urban areas).

2. Henceforth, except as noted, the term sacrifice ratio shall be taken as being the undiscounted employment cost of a one percentage point reduction of inflation. In the simulations that we present, the versions of the model used are either linear or nearly so, and therefore the magnitude of the disinflation is of no consequence. Similarly, since the model's ex post Okun coefficient is very nearly the same regardless of the way in which a disinflation is carried out, there is very little incremental information to be had from examining output sacrifices.

3. Ball actually computed an output sacrifice ratio of 1.8 which can be converted to an employment sacrifice ratio of about one using standard measures of the Okun coefficient of about 1-1/2 to 2 . Generally speaking, except for the sign, an unemployment sacrifice ratio and the employment sacrifice ratio computed from the same experiment will be similar. 

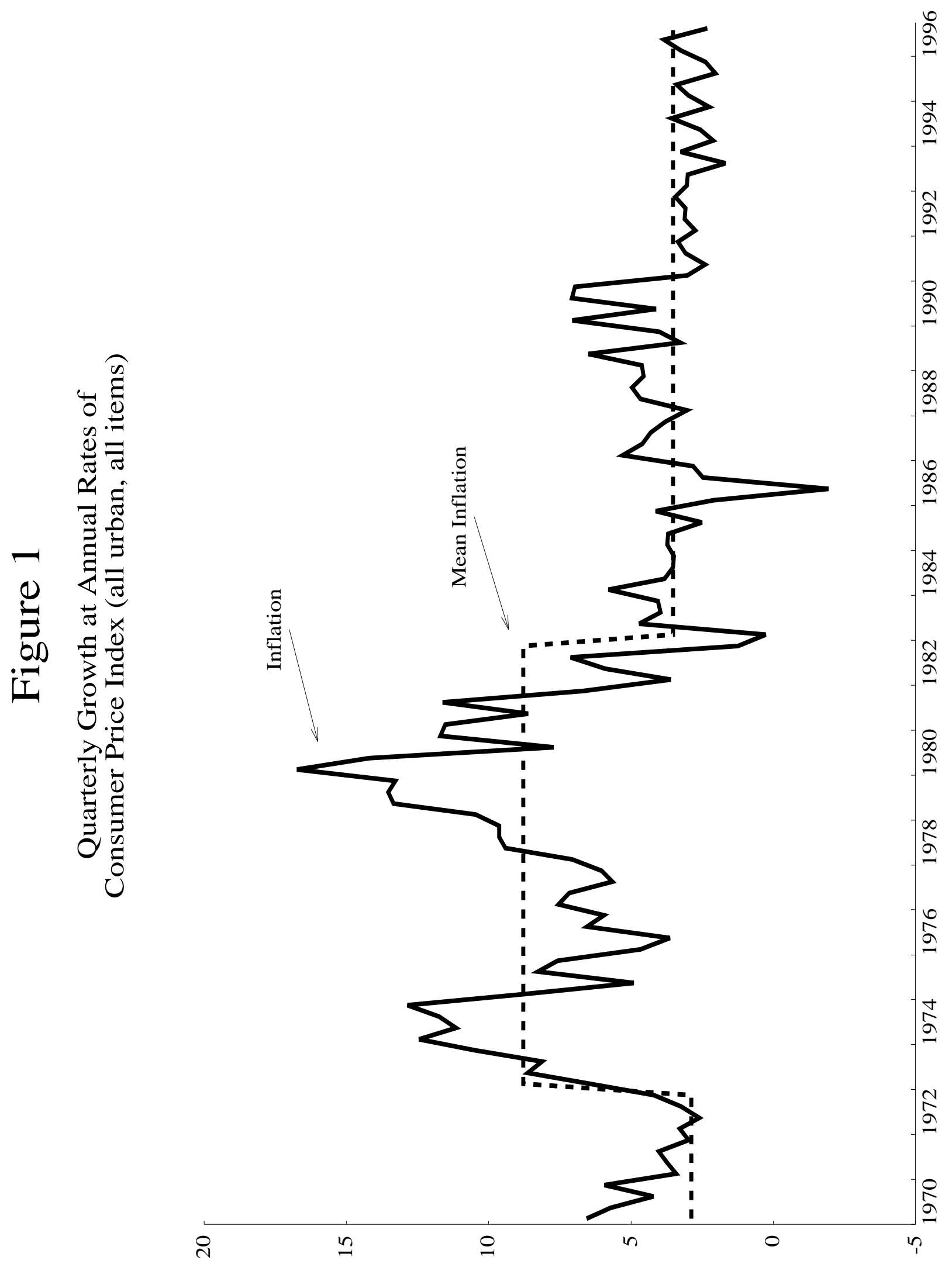
Through much of the 1990s, the staff of the Board of Governors have been working on a new macroeconometric model of the United States economy. In the spring of 1996, the first working version of the FRB/US model replaced the venerable MPS model for forecasting and policy analysis. As the name change hints, FRB/US is more than just a refurbishing of its predecessor. The builders of FRB/US sought to exploit the many changes in the economic modelling and econometrics that have taken place over the twenty-five years since MPS was first put into service. The wish list for the model was a long one. The new model had to fulfill a role in both forecasting and policy analysis. To serve as a tool of policy analysis, the model had to be able to characterize outcomes as arising from the conscious decisions of agents. In short, the agents represented by the model's behavioral equations had to be optimizing, albeit subject to constraints. The model had to produce results to well-posed policy questions that are sensible from the point of view of general equilibrium or systems properties. At the same time, goodness of fit, assessed on an equation-by-equation basis, remained a priority. The adoption of recent innovations in modeling technology has served to improve the tradeoffs that are inherent in reconciling these often conflicting objectives.

Disinflation involves the conscious act of a monetary authority to change the prevailing expectations of private agents. Unlike the bulk of earlier models, the FRB/US model can offer some meaningful insight on policy issues of this sort. Most macroeconometric models are not able to address the issue of changing expectations because their dynamic lag structures do not distinguish between sources of propagation that are attributable to intrinsic dynamics, meaning adjustment costs, irreversibilities, vertical input-output relationships and the like, and expectational dynamics, stemming from errors in expectations formation and learning. In this way, these models fall prey to the Lucas critique.

The FRB/US model addresses the Lucas critique: ${ }^{4}$ model dynamics stem from a confluence of intrinsic and expectational propagation mechanisms. Intrinsic adjustment costs are modeled using a polynomial adjustment costs (PAC) technology described by Tinsley (1993) and Brayton and Tinsley (1995). PAC technology avoids the empirical rejection of rational expectations models of optimizing behavior that have plagued the literature. This is done through a straightforward generalization from the more traditional level adjustment cost (LAC) specification, in which costs are quadratic in the level of the decision variable, to allow high-order adjust-

\footnotetext{
4. We say that FRB/US "addresses" rather than solves the Lucas critique in that the model lays out behavioral decision rules for private agents. This allows users to experiment with the expectational responses to policy interventions, as we do here in this paper. However since private decisions are not modeled simultaneously with and conditioned upon the (probably time-varying) behavioral decision rules for the monetary and fiscal authorities, it might be an overstatement to say that the current version of the model solves the Lucas critique.
} 
ment costs. ${ }^{5}$ An important advance with the new model is that it can be simulated using either model-consistent expectations, or expectations that are based on limited information, in this case generated from a vector autoregression.

\section{Table 1}

\section{Some Estimates of Sacrifice Ratios for the United States}

\begin{tabular}{ccccc}
\hline \multirow{2}{*}{ Reference } & Period & Method & \multicolumn{2}{c}{ Sacrifice Ratio } \\
\cline { 4 - 5 } & & & Output & Employment \\
\hline \hline Okun (1978) & various & econometric survey & $6-18$ & $2-6$ \\
Gordon (1982) & $1920-1921$ & calculation & 0.2 & -- \\
Gordon-King & $1954-1980$ & econometric & $4.3-5.8$ & -- \\
Sachs (1985) & $1981-1984$ & calculation & & -- \\
Blinder (1987) & $1982-1985$ & calculation & 3.0 & 1.7 \\
Mankiw (1991) & $1982-1985$ & calculation & $3.7^{1}$ & -- \\
Ball (1994) & $1969-1971$ & calculation & 2.8 & 2.1 \\
& $1974-1976$ & calculation & 2.9 & 1.9 \\
\hline MPS (1995) & $1963-1993$ & simulation & 3.6 & $1.5^{2}$ \\
\hline \hline
\end{tabular}

Notes: Okun's Law calculations used to convert from output sacrifice ratios to employment sacrifices are those of the reference author, except where otherwise stated. We ignore the small differences that arise between unemployment sacrifice ratios and employment sacrifice ratios and convert the sign of the former to positive.

1. Simulation figure refers to computations based on Sachs (1985) Table 8, p. 172.

2. Converted from output to employment using an Okun's Law of 2 as suggested by footnote 5, p. 170.

3. Based on a simulation of the July 1995 version of the DRI Quarterly Model of the U.S. Economy.

4. Unpublished results from a simulation conducted on the 1995 version of the MPS model.

5. Or adjustment costs in the moving-average of the level of the variable. It turns out that these are equivalent although sometimes the resulting estimates suggest one interpretation over the other. On this, see Tinsley (1993). 
It is this flexibility in the modeling of expectations that allows us to investigate the importance of expectations formation for the cost of bringing down inflation within a working, econometric macro model. The model also allows the use of learning rules to come to grips with the transition dynamics surrounding fundamental changes in the economic environment, including changes in the objectives of monetary policy. Following Sargent (1993), one might argue that "rational" expectations may be a meaningful characterization of an economy at its stochastic steady state, but it may be important to consider "nonrational" transition dynamics stemming from the learning of the new environment associated with a change in policy target.

The rest of this paper proceeds as follows. We begin, in Section 2, with a brief summary of the FRB/US model, focusing on those aspects of the model that are pertinent to the policy issue at hand. This naturally leads us to discuss wage and price determination and the characterization of monetary policy. Section 3 outlines our approach to learning. Section 4 considers disinflation experiments under VAR-based and model consistent expectations, with and without learning. We compare our results with those in the literature and with the estimated benefits of inflation reduction. The fifth and final section offers some concluding remarks and discusses directions for future research.

\section{The FRB/US Model}

This section reviews the structure and methodological underpinnings of FRB/US with a view towards providing an understanding of the sources of costly price and inflation adjustment. To facilitate this end, our discussion of the model will be brief and concentrated primarily on the wage-price block. The model's wage-price block is a bit more complicated than a single-equation specification for inflation, and so in order to show the value-added from this modest increase in complexity, we shall compare the model with standard Phillips curves. We begin, however, with the broader aspects of the model's construction.

\subsection{General Aspects}

In comparison with most working econometric models, including MPS, FRB/US is small, with about 300 equations overall, of which about 50 are behavioral. A large part of the reason for the smaller size is the higher emphasis placed on system properties in model evaluation. More so than in the past, the success or failure of FRB/US hinges on its ability to answer meaningful policy questions with a minimum of fuss. This means that behavior is more often modeled from a 'top-down' perspective than a 'bottom-up' one. About half of these behavioral equations are explicitly derived as decision rules governing the behavior of representative agents acting with foresight to achieve explicit objectives in the presence of constraints. 
One of these constraints is the information set to which agents have access in forming their expectations. As we shall see below, the model can be simulated with any of a number of different characterizations of the availability of information and its subsequent gathering over time. For the purposes of estimation, however, it was assumed that information is constrained to a small set of aggregate macroeconomic variables, summarized by a low-order vector autoregression (VAR) described below. This low-order VAR forms the core of the expectations generation system that is augmented by one or two other variables, the precise nature of which varies from agent to agent and from sector to sector.

Wrapped around this expectations structure are the decision rules which lay out the planned paths for the decision variables under control of each agent, given expectations and the costs of adjustment. In the case of financial variables, these intrinsic costs of adjustment are regarded as negligible; equilibrium is determined by arbitrage. ${ }^{6}$ However for real variables, the presence of adjustment costs means that agents must balance the cost of being away from their desired level for a variable with the cost of adjusting to get to that desired level. This compels them to plan ahead, subject to expected future conditions, to set out a path for the adjustment toward the desired level. An important step forward in the empirical performance of macroeconomic models based on decision rules is adoption of polynomial adjustment costs (PAC) in place of the traditional level-adjustment-cost (LAC) decision rules popularized by Tinsley (1970) and Hansen and Sargent (1980), among others. Relaxing the restriction that adjustment is costly only in the level of the decision variable dramatically reduces the problem of excess residual autocorrelation that has traditionally plagued empirical tests of macroeconomic decision rules.

And at its heart, FRB/US is a neoclassical growth model. That is, once all the dynamic adjustment is complete, the model settles down on a balanced growth path with consumption determined by wealth, wealth determined in large part by productivity and steady-state real interest rates, and real interest rates determined by the savings-investment decisions of private agents in concert with government. The model is non-Ricardian. Of the several reasons which account for this feature, the most important is that risk-averse agents 'overdiscount' their future disposable income, in the same spirit as the Blanchard (1985) model of perpetual youth. This means that a portion of government debt is considered to be net wealth. More generally, fiscal policy can act upon the long-run equilibrium of the economy through purchases, transfers, government debt, and distortionary taxes. Developments in the understanding of the econometrics of stochastically trended variables play a substantial role in the determination of the characteristics of the long-run

6. With the exception of the monetary policy rules, which have the form of interest-rate reaction functions, we shall have nothing further to say about the modeling of financial variables. Interested readers are invited to consult Kozicki et al. (1996), or Brayton and Tinsley (1996) for details. 
equilibrium of the model. But since we take as given that to be useful for policy analysis, a model must contain within its structure a well-defined steady state, this requirement has, upon occasion, overridden the results of cointegration tests.

\subsection{Modeling Wages and Prices}

Inflation dynamics in the FRB/US model are driven by adjustment costs in nominal prices and wages and, for some specifications, by the characterization of expectations and learning. Let us set aside expectations for the moment so as to focus on the structural determinants of costly disinflation in the model. We have already noted that the existence of costly adjustment obliges agents to plan ahead to achieve their objectives for some date in the future. The target level of the variable in question may be moving over time, which in turn means that agents lay out a path for the target itself as well as a plan to close the gap between current levels of wages (or prices) and the target level.

Taking the target level of the producer price as given, the job of firms as price setters is to choose the producer price, $p$, to minimize:

$$
L=\sum_{i=0}^{\infty} \beta^{i}\left[b_{0}\left(p_{t-i}-p_{t-i}{ }^{*}\right)^{2}+b_{1}\left(p_{t-i}-p_{t-i-1}\right)^{2}+\sum_{k} b_{k+1}\left(\Delta^{k} p_{t-i}-\Delta^{k} p_{t-i-1}\right)^{2}\right]
$$

where $p^{*}$ is the target price, $b=\left[b_{0}, b_{1}, \ldots, b_{k+1}\right]$ is a vector of parameters measuring the intrinsic costs of adjustment as well as the cost of being away from the target price, and $\beta$ is the subjective rate of discounting. ${ }^{7}$ Equation (1) is more general than the standard level adjustment cost (LAC) problem in the costs might be borne in adjusting in higher-order changes in prices, as determined by $b_{2}$ and $k{ }^{8}$ Just as Nickell (1985) has shown for the LAC problem, the Euler equation derived from this problem can be solved to arrive at an error-correction representation of the following form:

$$
\Delta p=-A(1)\left(p_{t-1}-p_{t-1}^{*}\right)+\sum_{j=1}^{k} \gamma_{j}(b) \Delta p_{t-1}+\sum_{i=0}^{\infty} \rho_{i}(\beta, b, k) E_{t-1} \Delta p_{t+i}{ }^{*}
$$

where $A(L)=1+a_{1}(b) L+a_{2}(b) L^{2}+\ldots+a_{k+1}(b) L^{k+1}$. Equation (2) differs from what one would derive from the LAC model in two significant ways: first, the LAC model implies that

7. In this equation and all others, all variables other that those naturally expressed as rates, are expressed in natural logarithms, unless otherwise noted. Variables expressed as rates include interest rates and inflation. 8. Tinsley (1993) shows that extending the quadratic adjustment cost model either to allow quadratic costs of higher-derivative changes, as in equation (1), or in moving averages of the level of the decision variable, can produce the same Euler equation. Which interpretation is most useful will vary from case to case, often depending on the specific empirical results. 
lags in $\Delta p$ do not appear in the decision rule; second, under LAC the forward term in which the $\Delta p_{t+i}{ }^{*}$ appears is constrained to be a geometrically declining lead. Under PAC technology, both of these restrictions are relaxed. It is worth emphasizing, however, that notwithstanding the relaxation of the constraints noted, important testable restrictions across parameters still exist.

We shall outline in brief form the empirical results for our price equation, but before doing so, we need to discuss the specification of target variables, $p_{t+i}{ }^{*}$, and expectations thereof.

It is useful to dichotomize the determinants of the target price level into stationary and non-stationary components. The specification of the stationary components is essential for satisfying long-run equilibrium conditions: prices equal marginal cost (plus a fixed markup) in the long run, and the producer real wage equals the marginal product of labor. The stationary components of target variables impart dynamics on the model, in this case, a cyclical markup.

The first-order conditions for profit maximization given Cobb-Douglas production technology in three factors imposes the necessary long-run restriction on wages and prices, given productivity and the price of energy. ${ }^{9}$ This determines the nonstationary component of the target price:

$$
\hat{p}_{t}=\delta+\phi\left(w_{t}-\lambda_{t}\right)+(1-\phi) p_{t}^{e}+\varepsilon_{t}
$$

where $w$ is the wage rate, $\lambda$ is trend labor productivity, and $p^{e}$ is the price of energy.

Prices are assumed to be set by firms and wages to be set or negotiated jointly by firms and workers such that equation (3) holds as an equilibrium implication of the combined behavior of wages and prices. One way to think of the bargaining process that might bring this about is that the markup of prices over costs (and thus the real wage) moves with excess supply of labor in reflection of the ebb and flow of bargaining power over the business cycle. Adding this stationary component to $\hat{p}_{t}$ and taking expectations yields the target price:

$$
p_{t+i}^{*}=E_{t-1}\left[\hat{p}_{t+i}+\phi^{p} U_{t+i}\right]
$$

where $\hat{p}$ is the solution to equation (3) above, ignoring the error term, and $\phi^{p} U_{t+i}$ is the cyclical portion of firms' target mark-up of prices over costs. A target wage rate equation also exists, modeled in an analogous fashion, and contains its own cyclical determinants. These two equations jointly satisfy equation (3) and, in steady state, settle down on the equilibrium real wage.

9. The production function is Cobb-Douglas with constant returns to scale in three factors, capital, labor and energy. A constant term picks up the equilibrium level of price mark-ups over cost. 
The estimated PAC wage and price equations indicate that there is stickiness in rates of change and in the acceleration of each. From the estimated equations, the cost parameters can be computed. In the case of the price equation, we have $\left(b_{0}, b_{1}, b_{2}\right)=(0,99.1,-17.5)$. The zero coefficient on the LAC term assumes that it is not costly for firms to adjust prices at the steadystate rate, or that the cost of price adjustment on the steady-state path is invariant to the inflation rate. This is a homogeneity restriction, necessary for the natural rate hypothesis to hold, which in turn implies the wage-price block is consistent with any targeted inflation rate. The dominant feature of the PAC technology for price-setting firms is the large coefficient penalizing changes in the inflation rate; inflation is quite sticky in FRB/US. Interestingly, $b_{2}<0$ means that while firms find changes in inflation costly, when inflation must change, firms prefer that it take place rapidly. Finally, we observe that the estimates also show that price setting behavior carries a weight of 43 percent on forward elements and 57 percent on predetermined elements.

\section{Table 2}

\section{Some Estimates of the Producer Price Equation 1963Q1 - 1994Q4}

\begin{tabular}{cr}
\hline \hline$\Delta p=0.10\left(p_{t-1}-p_{t-1}{ }^{*}\right)+0.38 \Delta p_{t-1}+0.19 \Delta p_{t-2}$ & $S E E=0.0025$ \\
$+0.38 \Delta\left(\frac{\tilde{p}^{e}}{p}\right)-0.05 \Delta\left(\frac{\tilde{p}^{e}}{p}\right)_{t-1}+0.43 \sum_{i=0}^{\infty} \tilde{\rho}_{i}(A, \beta, b, k) \Delta p_{t+i} *$ & $R^{2}=0.88$ \\
\hline$p_{t}^{*}=0.98(w-\lambda)+0.02 p^{e}-0.003 u$ & $J(20)=0.47$ \\
\hline \hline
\end{tabular}

Notes: variable definitions: $p$ is the price of output excluding government, farm and energy; $p^{*}$ is the desired price; $p^{e}$ is the price of energy consumption; $\Delta\left(\tilde{p}^{e} / p\right)$ is the change in the scaled relative price of energy consumption; $w$ is the nominal wage rate measured by the employment cost index; $\lambda$ is the level of trend labor productivity for the production sector defined above; and $u$ is the level of the demographically adjusted unemployment rate. Some constant terms have been suppressed. $B G(n)$ is probability value associated the Breusch-Godfrey test of serial correlation for up to $n$ lags. $J(k)$ is the probability value associated with Hansen's test of overidentifying restrictions.

Most of the empirical specifications of PAC equations include extra terms designed to capture idiosyncratic elements of the particular sector's behavior. The price and wage equations are no different. The producer price equation contains a term (contemporaneous and lagged) that captures the faster pass-through into producer prices of energy prices than other costs. Table 2 provides the highlights of the empirical results for the price equation. The structure of the wage equation is similar to that of prices and so we shall not explicitly review the empirical specifica- 
tion here. It is worth mentioning, however, that the extra terms are more numerous in the wage equation; they include, a dummy for the Nixon wage-and-price controls, a relative minimum wage variable, and a variable capturing the implications of payroll taxes. Also, as it turns out, three lags of the change in the wage rate enter the wage equation, and wages turn out to be stickier than prices.

The results above contrast with pure price stickiness models such as Taylor (1980), Calvo (1983), and Rotemberg (1983) since, without inflation stickiness, these models imply that costless disinflation is feasible. Costly inflation adjustment, as we have here, is also a feature of the real wage contracting model of Buiter-Jewitt (1981) and Fuhrer-Moore (1995), and of standard accelerationist Phillips curves. It implies that disinflation will be costly in terms of forgone output regardless of expectations. That is, while expectations formation in general and the credibility of policy in particular may impinge on the results of disinflation experiments, they will not do so in such as way as to reduce the costs of disinflation to zero. Since the standard accelerationist Phillips curve specifies that inflation is costly to adjust but does not provide an avenue for policy to affect these costs, the FRB/US wage-price specification encompasses the accelerationist Phillips curve model and extends it by allowing both forward- and backward-looking elements to influence inflation and by disentangling the intrinsic and expectational sources of propagation.

\subsection{Expectations Formation}

In laying out equation (4), we did not discuss how expectations of future target prices are formed. In use for forecasting, and during the course of estimation, it is assumed that expectations formation can be represented by a low-order vector autoregression. Effectively, what this does is restrict the full, reduced-form of the model-consistent solution to one of a smaller order that might arguably be more in keeping with what might be used by agents facing costly information collection and processing. Thus, we think of the VAR-based expectations solution of the model as being a reasonable approximation of the limited-information solution of the model. ${ }^{10}$

The precise VAR used varies from sector to sector, but three core equations are used in all cases. These core VAR variables are the output gap, the inflation rate, and the nominal federal funds rate. This core VAR represents the aggregate information that is available to all agents in the economy. On top of this, agents in each sector have at their disposal local information that is useful for forecasting variables of concern to them. In the spirit of the 'island paradigm' of Lucas (1972) among others, localized agents take macro-aggregate variables as given, and so the struc-

10. The use of VAR-based expectations also obviates the need to use of simultaneous equations methods such as FIML or three-stage least squares which, while feasible in principle, turn out to be too unwieldy to pursue in practice for a model the size of FRB/US. 
ture of these local VARS is restricted such that the macro-aggregate variables of the core VAR affect the local variables, but not vice versa.

The specification of the core VAR differs from traditional VARs in two small but important ways. The structure is summarized in equations (5) and (6) below. First, there are restrictions imposed on the $A\left({ }^{\circ}\right)$ matrix to ensure the VAR is consistent with any target level of inflation. The second difference and more important difference -- related to the first -- is that the long-run levels of the variables are constrained by transversality or endpoint conditions, the $x^{\infty}$ in equations (6) below:

$$
\begin{gathered}
A(L) x=u_{t} \\
x=\left[\begin{array}{l}
y-y^{\infty} \\
\pi-\pi^{\infty} \\
r-r^{\infty}
\end{array}\right] \quad u=\left[\begin{array}{l}
u^{y} \\
u^{\pi} \\
u^{r}
\end{array}\right]
\end{gathered}
$$

In this system, $y$ is the deviation of output from potential output, measured in percent; $\pi$ is inflation; and $r$ is the nominal federal funds rate. With a traditional (stationary) VAR, the sample mean serves as the "endpoint" for the system; that is, the point upon which forecasts will eventually settle. In the core VAR used in FRB/US, this is generalized to permit systematic changes in long-run conditions. Since FRB/US is a natural rate model, the endpoint constraint for the output gap is trivially identical to zero. For inflation and the federal funds rate, however, the endpoint constraint represents the private sector's long-run expectation for inflation and, through the imposition of the Fisher identity, the real interest rate, respectively. In the data, the endpoint for the (nominal) federal funds rate is computed from the implied forward rates at the far end of long-term bond rates, less a term premium which is taken as constant in the long run. The endpoint for inflation is taken from a survey of inflation expected over a 10-year period kept by the Federal Reserve Bank of Philadelphia.

The presence of endpoint variables in the VAR reflects the finding of nonstationarity in nominal interest rates in the historical data. This could represent permanent or near-permanent shifts in the real interest rate. Alternatively, it could represent either shifts in the (perhaps implicit) targeted inflation rate, or the inability of the Fed to achieve a fixed (implicit) target due to unfavorable shocks. The data suggest that both real rate movements and inflation movements have been at work.

The important point to take from the inclusion of these endpoint constraints is that they can move endogenously. In the absence of moving endpoints, one is faced either with interest 
rates that are "too smooth" in in-sample simulation, relative to the historical data, or "too volatile", depending on whether one models nominal interest rates as stationary or integrated. ${ }^{11}$ By itself, this modeling strategy is a topic worthy of a lengthy discussion that we cannot provide here; interested readers can find the pertinent arguments in Kozicki and Tinsley (1996).

\section{Table 3}

\section{Estimates of the Core VAR 1963Q1 - 1994Q4}

\begin{tabular}{ccc}
\hline \hline$=0.62 \pi_{t-1}+0.03 \pi_{t-2}+0.30 \pi_{t-3}-0.11 \pi_{t-4}+0.16 \pi^{\infty}$ & \\
$+0.16 r_{t-1}-0.26 r_{t-2}+0.01 r_{t-3}+0.07 r_{t-4}+0.01 r^{\infty}$ & $S E E=1.13$ \\
$+0.07 y_{t-1}-0.03 y_{t-2}+0.05 y_{t-3}+0.03 y_{t-4}$ & $R^{2}=0.26$ \\
$y=-0.02 \pi_{t-1}+0.05 \pi_{t-2}-0.04 \pi_{t-3}-0.03 \pi_{t-4}+0.03 \pi^{\infty}$ & \\
$-0.01 r_{t-1}-0.40 r_{t-2}+0.29 r_{t-3}-0.05 r_{t-4}+0.18 r^{\infty}$ & $S E E=1.12$ \\
$+1.09 y_{t-1}-0.07 y_{t-2}-0.02 y_{t-3}-0.05 y_{t-4}$ & \\
\hline$=0.14 \pi_{t-1}-0.00 \pi_{t-2}+0.05 \pi_{t-3}-0.12 \pi_{t-4}-0.06 \pi^{\infty}$ & \\
$+0.99 r_{t-1}-0.44 r_{t-2}+0.49 r_{t-3}-0.11 r_{t-4}+0.07 r^{\infty}$ & \\
$+0.31 y_{t-1}-0.13 y_{t-2}-0.10 y_{t-3}+0.02 y_{t-4}$ & $S E E=1.14$ \\
\hline \hline
\end{tabular}

Notes: The specification shown is equivalent to the representation of equations (5) and (6). Variable definitions: $r$ is the nominal federal funds rate measured on an effective basis; $\pi$ is the quarterly change in the chain-weighted personal consumption price index, measured at annual rates; $y$ is the deviation of output from its trend, measured in logarithms. $r^{\infty}, \pi^{\infty}$ are defined as noted in the text.

The question at hand is what governs the movements of these endpoints? On this, we shall focus on the movements of the endpoint for inflation, and since inflation is a monetary phenomenon, it stands to reason that the endpoint for inflation is determined by monetary policy. This is

11. The similarity of this issue to that of the "excess volatility" or "excess smoothness" of consumption for a given data generating process for income is not a coincidence. The same issues of identification of the "size of the unit root" and its origin are at work here. 
not to say that the endpoint is the long-run target for monetary policy. Rather, it is the role of the monetary authority to elicit changes in private agents' expectations so as to guide expected inflation in the long run, $\pi^{\infty}$, to the target inflation rate: $\pi^{*}$. Notice, then, that we have implicitly divided expectations formation into two parts, distinguished by frequency: we have expectations over the short run given, in some cases at least, by the VAR: $E\left[x \mid x^{\infty}\right]$, and we have lower frequency dynamics, governed by movements in $x^{\infty}$. This presents a myriad of hypothetical experiments regarding the response of private agents to policy interventions. In particular, as we shall demonstrate in the next section, VAR-based expectations can be replaced with model consistent expectations. And both systems of expectations formation allow instantaneous recognition of a change in the policy target, or learning. We regard this flexibility as one of the major contributions of the model.

\subsection{Monetary Policy}

Consistent with the handling of expectations, monetary policy in the model is also flexible. The most coherent characterization is that of monetary policy being governed by explicit feedback rules that have as their medium-to-long-term objective the establishment and maintenance of a nominal anchor. It is under these circumstances that the consistency of private expectations and policy intentions can be addressed.

The monetary policy rule that has been used in our assessments of model properties is the very same equation that is used in VAR to model expectations. In this instance, the core VAR's federal funds rate equation is more than simply a linearized, restricted-information solution to the larger system but is literally the policy rule. When the model is simulated in this mode, it is assumed that the process of learning the authority's rule and target is already complete. This completes the chain of logic on the estimation strategy that was followed: VAR expectations are used to identify the expectational dynamics of the model, PAC technology then selects the intrinsic dynamics, and the VAR-based policy rule validates the expectations that private agents were assumed to have used in the first place. For the purposes of policy analysis, however, one can replace the VAR-based policy rule with another rule and examine the process of the adaptation of private expectations to a "data generating process" for policy that is different from that of history.

The VAR rule represents the average historical experience over the period from 1963 to 1994. We are more interested in specific episodes and in specific rules, and so in our simulations below, we pay scant attention to the VAR rule. Instead, we consider two alternative rules. Both of these rules approximate monetary policy in the United States over the period during and after the Volcker disinflation. One is the well-known Taylor $(1993,1994)$ rule. The other carries the same 
arguments as the Taylor rule but allows for a richer dynamic structure; we refer to this rule as the Post-1970s rule.

The Taylor rule is very simple federal funds rate reaction function, loosely fitted to the experience of the 1980s. It calls upon the Fed to respond to contemporaneous deviations of inflation from its target level and to deviations of (the log of) output from its potential level. Both behavioral arguments to the reaction function carry the same 0.5 coefficient. We have replaced the contemporaneous value of inflation in Taylor's specification with a four-quarter moving average. Otherwise, the rule we use is as Taylor has written it.

The Taylor rule has two features that some observers might take as being unusual. The first is that the endogenous variable is written in levels instead of changes. A rule written in levels requires the authority (and the modeler) to have a good estimate of the steady-state real interest rate, shown here as $r r^{*}$. In principle, a rule written in $\Delta r$ could be allowed to error-correct to an unknown $r r^{*}$. However, arriving at any rule with attractive properties for a wide range of economic circumstances would oblige the researcher to begin with a reasonable idea of $r r^{*}$; so the differences between good rules written in $\Delta r$ and $r$ may be more apparent than real. The second noteworthy feature of the Taylor rule is that there are (effectively) no dynamics in the equation. This issue we can address with our Post-1970s rule. The two rules are shown in Table 4.

The lag structure of the Post-1970s rule implies that the response of the federal funds rate to deviations of target variables from their desired levels builds over time. The other important difference between the Taylor and Post-1970s rule is that the latter is a much more forceful rule. The steady-state coefficient on inflation in the Post-1970s rule is about 3, or six times as large as that of the Taylor rule. Similarly, the steady-state weight on the output gap is about 2, or four times as large as the Taylor rule. Both of these observations will turn out to be important facts when we consider the implications of federal funds rate surprises for learning in what follows below. 
Table 4

Two Federal Funds Rate Reaction Functions

\begin{tabular}{cc}
\hline \hline$r=r r^{*}+\sum_{i=0}^{3} \pi_{t-i} / 4+0.5\left(\sum_{i=0}^{3} \pi_{t-i} / 4-\pi^{T}\right)+0.5 y_{t}+\mu_{t}$ & $\begin{array}{c}\text { Taylor Rule } \\
\text { (calibrated) }\end{array}$ \\
$r=0.62 r_{t-1}-0.06 r_{t-2}+0.25 r_{t-3}+0.07 r_{t-4}$ & Post-1970s \\
$-0.09\left(\pi-\pi^{T}\right)+0.17\left(\pi_{t-1}-\pi^{T}\right)+0.07\left(\pi_{t-2}-\pi^{T}\right)+0.23\left(\pi_{t-3}-\pi^{T}\right)$ & Rule \\
$+0.84 y_{t}-0.21 y_{t-1}-0.10 y_{t-2}-0.27 y_{t-3}$ & $79 \mathrm{Q} 4-94 \mathrm{Q} 4$ \\
$+(1-0.62+0.06-0.25-0.07)\left[r r^{*}+\sum_{i=0}^{3} \pi_{t-i} / 4\right]+\mu_{t}$ & $S E E=1.17$ \\
\hline \hline
\end{tabular}

Notes: Variable definitions: $r$ is the nominal federal funds rate measured on an effective basis; $\pi$ is the quarterly change in the chain-weighted personal consumption price index, measured at annual rates; $y$ is the deviation of output from its trend, measured in logarithms.

\subsection{Learning}

As we have already discussed, expectations formation in the model can be dichotomized into parts: expectations over the short to medium term, and expectations of the long-term, that is, of the endpoints. We can illustrate differences in the method of forming expectations in the short and medium term through our choice of model-consistent expectations or VAR-based expectations. We can also investigate expectations formation at a lower frequency by modeling expectations of the endpoint for inflation. Table 5 illustrates the connection between our dichotomization of expectations and the literature. We think of issues such as "credibility" and "reputation" as having to do with knowledge of, belief in, and acceptance of, the target rate of inflation of the monetary authority; this is a low-frequency concept that can be made distinct from the dynamic resolution of expectations errors along the transition path to the new target inflation rate. ${ }^{12}$ Expectational errors in the short run -- apart from those attributing to incorrect perceptions of the target -- may come from limited information, as we have when we use VAR-based expectations, or from unanticipated shocks.

12. The distinction between expectations of the long run for inflation and the short run is often blurred in academic treatments of the subject which often use models with no dynamic features other than credibility. 
The usefulness of this distinction is best seen by considering the example of a preannounced disinflation. If the public believes the Fed to be sincere in its announcement, and to be capable of carrying out the policy, the announcement is credible. ${ }^{13}$ In this case, the endpoint for inflation jumps discontinuously to the new, announced level. If private agents also form expectations using the entire structure of the model, then expectations are rational expectations in the sense of Muth. Full credibility combined with model consistency and pre-announcement gives perfect foresight. This case is represented by the north-east quadrant of the body of Table 5. There is, however, no reason to assume that because agents find an announcement fully credible, they also have access to full information. In this case, agents use limited information -- VAR-based in our cases -- to summarize the economy and the north-west quadrant applies. The lower part of the table refers to cases of learning. In these cases, agents use observable information to update their expectations of the true target rate of inflation.

\section{Table 5}

\section{A Mapping Between Modelling of Expectations in FRB/US and the Venacular}

\begin{tabular}{|c|c|c|c|}
\hline \multicolumn{2}{|c|}{ short- to medium-term --> } & \multicolumn{2}{|c|}{ dynamic expectations formation } \\
\hline \multicolumn{2}{|c|}{ long-term } & VAR-based & Model Consistent \\
\hline \multirow{2}{*}{$\begin{array}{c}\text { endpoint } \\
\text { expectations }\end{array}$} & discontinuous & $\begin{array}{l}\text { limited information } \\
\text { but credible }\end{array}$ & $\begin{array}{l}\text { 'rational' and credi- } \\
\text { ble (perfect foresight) }\end{array}$ \\
\hline & continuous & $\begin{array}{l}\text { limited information } \\
\text { and learning }\end{array}$ & $\begin{array}{l}\text { 'rational' but not } \\
\text { credible; learning }\end{array}$ \\
\hline \multicolumn{4}{|c|}{$\begin{array}{l}\text { Notes: By 'discontinuous', we mean that the endpoint for inflation is jumps instantaneously to the new } \\
\text { target value; 'continuous' means that the expected target moves endogenously and continuously in } \\
\text { response to observable information; that is, that agents learn adaptively. }\end{array}$} \\
\hline
\end{tabular}

There is a substantial literature documenting a number of ways one could model endogenous learning of the target rate of inflation. Bullard (1991) provides a good, short survey at an elementary level with Sargent (1993) offering a more in-depth analysis, but still readable by nonspecialists. In our simple treatment, we assume that agents know with certainty the rule that is being used to conduct monetary policy but regard the target rate of inflation as being a random variable, the behavior of which may be reasonably approximated by a random walk. Under these circumstances, regardless of the particular rule, there are two source of uncertainty emanating

13. See Blackburn and Christensen (1985) for a good survey of credibility of monetary policy. 
from monetary policy: a transitory shock to the federal funds rate itself, and a once-and-for-all shock to the target. Agents must infer the target rate of inflation by solving a signal extraction problem. Let us take the Taylor rule, which we repeat for convenience, as an example:

$$
r=r r^{*}+1.5\left(\sum_{i=0}^{3} \pi_{t-i} / 4\right)+0.5 y_{t}-0.5 \pi_{t}^{T}+\mu_{t}
$$

Agents observe $\Delta r$ and need to estimate $\pi^{T}$ from their observations. Changes in the federal funds rate are given by:

$$
\Delta r=f(\text { observables })-0.5 \Delta \pi^{T}+\mu_{t}+\mu_{t-1}
$$

We assume the actual law of motion for the target rate of inflation follows a random walk:

$$
\pi_{t}^{T}=\pi_{t-1}^{T}+v_{t}
$$

Using this, let the surprise part of the change in the federal funds rate be:

$$
\lambda_{t}=\mu_{t}-\mu_{t-1}-0.5 v_{t}
$$

Only the left-hand side of equation (10) is observable. Assuming that both $\mu$ and $v$ are independently and identically distributed, the solution to the signal extraction problem is for agents to use the average occurrence of the shocks, as measured by the signal-to-noise ratio of the two disturbances, as their tool for forecasting the target inflation rate:

$$
E_{t} v_{t}=\left[\frac{0.5^{-2} \sigma_{v}^{2}}{0.5^{-2} \sigma_{v}^{2}+4 \sigma_{\mu}^{2}}\right] \lambda_{t}=k \lambda_{t}
$$

This means, in the parlance of Kalman filtering, that agents will update their perceptions of the inflation target by the Kalman gain, $k$ :

$$
\pi_{t}^{*}=\pi_{t-1}^{*}+k \lambda_{t}
$$

In principle, one could estimate the model of expectations updating and allow $k$ to be time-varying. If, for example, a monetary authority had been practicing a policy of allowing the inflation rate to drift, as our learning model says, and then reformed itself to fixed target, then $\lim _{t \rightarrow \infty} \sigma_{v}^{2}=0$ and $\lim _{t \rightarrow \infty} k=0$, and the data generating process for the target would eventually be perceived as being stationary. Our efforts in this area are ongoing but success has been elusive to date. Thus, for the experiments of the next section, we will be experimenting with a variety of constant gain specifications. 


\subsection{Numerical Issues}

We will be considering learning for both VAR-based and model-consistent expectations. Solving a problem of this nature under VAR-based expectations is straightforward. Under modelconsistent expectations, however, one must solve for the values of endogenous variables subject to agents' expectations of future values of endogenous variables, which are conditional on their (possibly incorrect) beliefs of the target rate of inflation. That is, expectations must be rational from the perspective of private agents, not the policy maker. This will not, in general, be the perfect foresight solution of the model that one could compute using standard extended path techniques such as Fair and Taylor (1980). The monetary authority signals to private agents that their beliefs are incorrect by setting the federal funds rate in ways that are inconsistent with private agents' beliefs. Doing so induces agents to update their beliefs until such time as the perceived rule and the actual rule coincide. This means that the model has to be solved over and over again, once for each date, so that the model can be shocked and beliefs updated.

Solving this problem is made considerably simpler by linearizing the model and then taking advantage of relatively new methods of representing linear rational expectations models. ${ }^{14}$ We use the method of Anderson and Moore (1985) to compute the VAR representation of our linear rational expectations model. This transforms the learning problem into a recursive one, dramatically shortening the time necessary to conduct our experiments. At the same time, it increases the reliability of our results by eliminating problems associated with incorrect terminal conditions that are associated with extended path solution methods.

\section{The Costs of Disinflation}

We are interested in the employment costs of a permanent one percent disinflation. ${ }^{15} \mathrm{We}$ compute the sacrifice ratio under a variety of different conditions. To provide benchmarks, it is useful to begin by setting aside learning and conducting one disinflation experiment with each of the full-information and limited-information versions of the model, under the assumption of full credibility. Recall that under these circumstances, we reduce the target inflation rate by one percentage point and the perceived target drops simultaneously. For this benchmark case, we use the Taylor rule. The results are summarized graphically in Figure 2 below.

14. Since FRB/US is close to linear, there is little lost from linearizing the model.

15. The model is very nearly linear so the magnitude of the disinflation is unimportant. What is more important is the "permanence" since one cannot reasonably argue that the costs of disinflation can be considered if the lower inflation rate cannot be sustained without incurring further costs. This means that the structural stability of the model is crucial to the results. 


\section{Figure 2}

FRB/US Disinflation Experiments (deviations from base case)

Limited Information versus Model-Consistent Expectations Instantaneous Recognition of Policy Change from Fed Funds Rate Surprises

Inflation and Expected Target Inflation

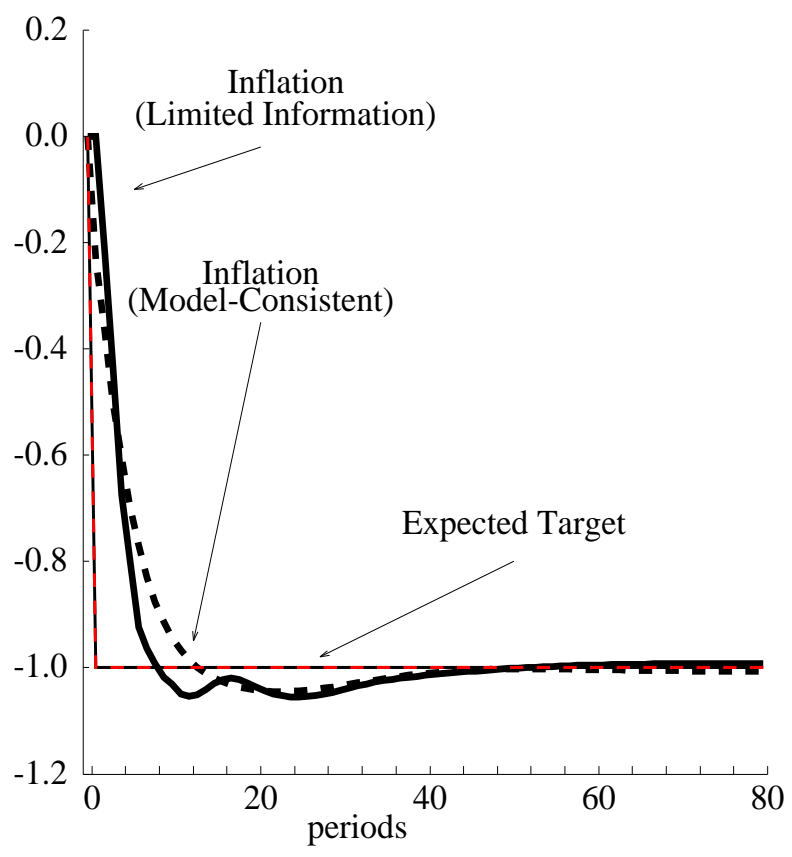

Nominal Federal Funds Rate

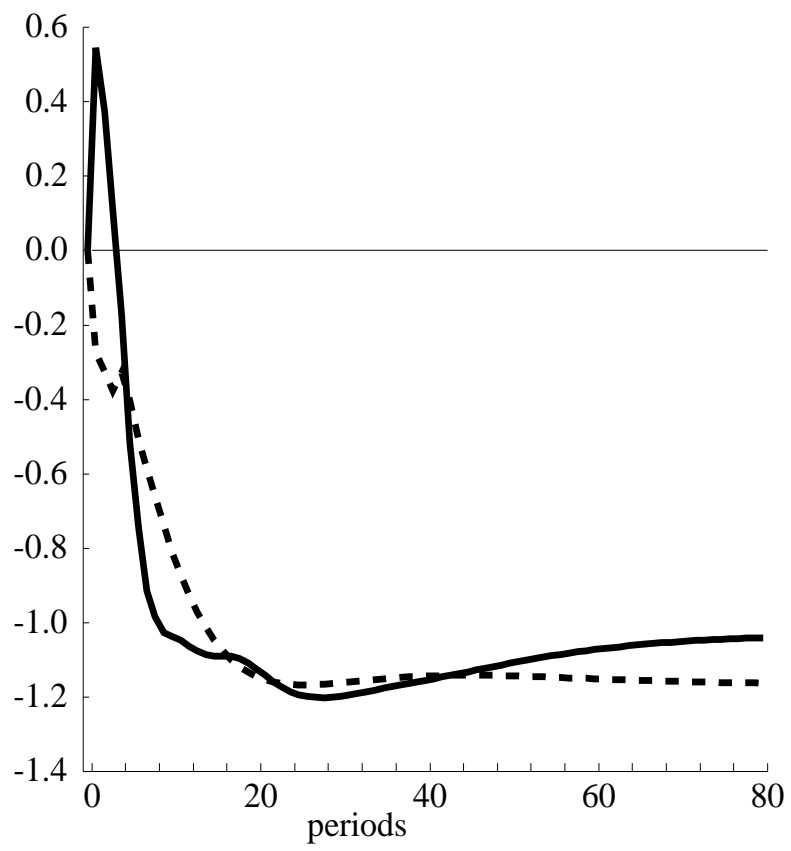

Unemployment Rate

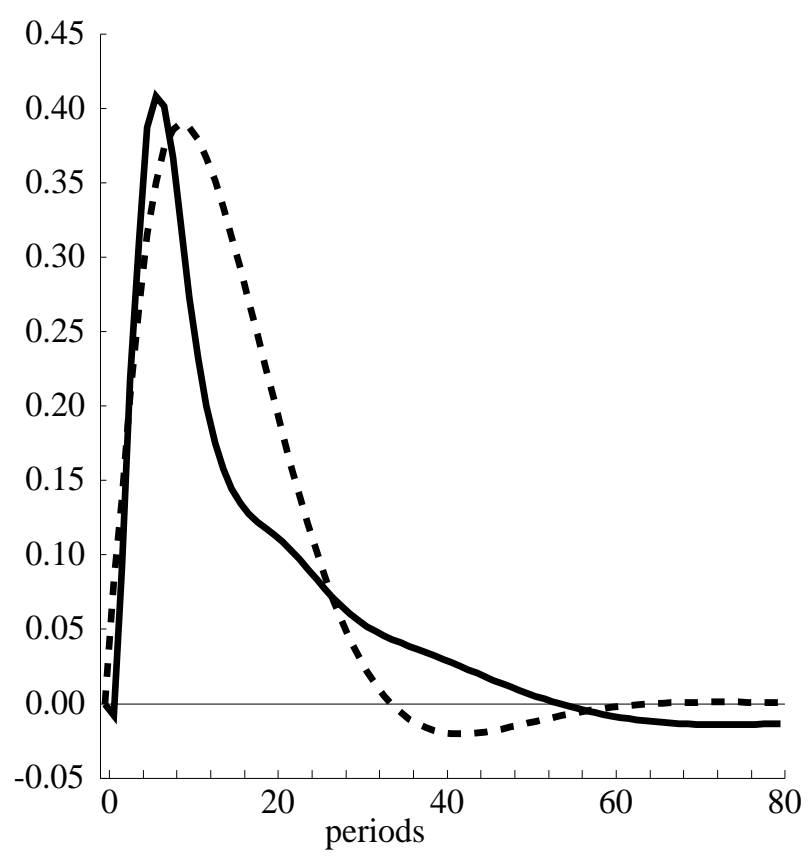

5-year Government Bond Rate

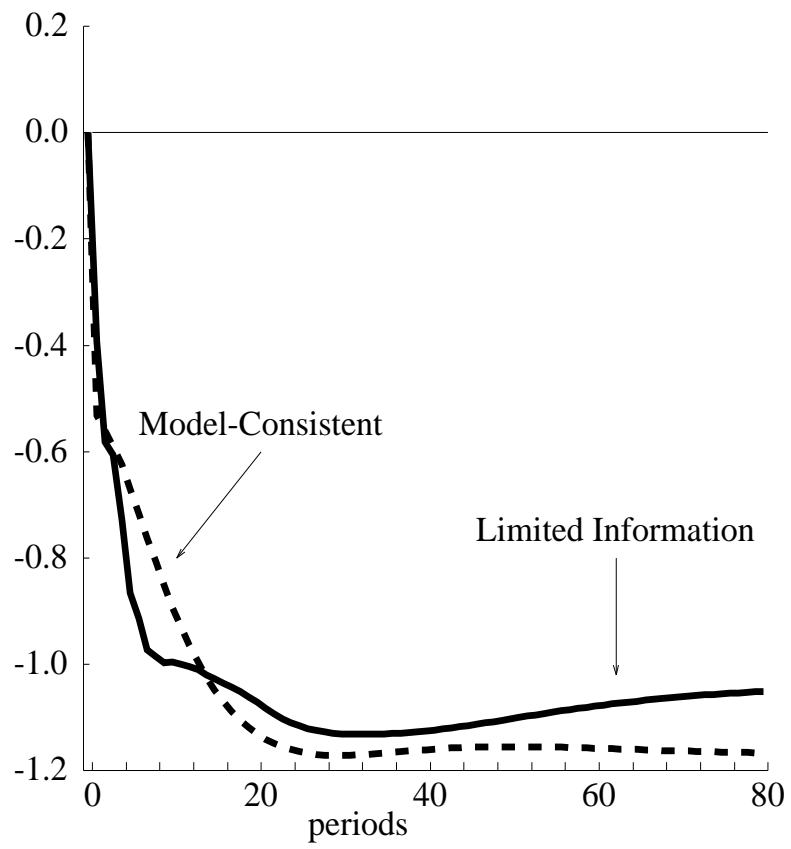


Perhaps the most striking thing about Figure 2 is the similarity of the two simulations. When monetary policy is fully credible, the dynamic movements of key variables are quite comparable. There are some noteworthy differences, but they are relatively minor. For example, full credibility permits the nominal federal funds rate to fall immediately in the model-consistent case, but not so in the limited-information case. There is also a small low-frequency secondary cycle in the limited-information case, and inflation begins its descent a bit later in the limited information case. The overall similarity of the results says two things about the model: first, that granting the monetary authority full credibility is giving agents a lot of information, and second, that the VARrepresentation of expectations encompasses quite well the information agents need to forecast future events with reasonable accuracy, for this shock. To understand this, note that disinflation is initiated by a disturbance to the federal funds rate, a variable that appears directly in core VAR. The disinflationary impetus -- beyond what credibility alone provides -- operates through the unemployment rate, and the output gap, which moves in parallel with unemployment for shocks from the demand side of the model, also appears in the core VAR. Finally, inflation itself appears in the core VAR. Given this information, it is perhaps not entirely surprising that the two disinflations are broadly similar.

What of our sacrifice ratios? Table 6 shows that the sacrifice ratio for the model-consistent expectations simulation with perfect credibility ends up being about 1.6 percentage points after 20 years. For the limited-information simulation, the corresponding number is $1.4 .{ }^{16}$ Referring back to Table 1, a benchmark figure for the sacrifice ratio (in employment space) might 2 to 2.5 . We see, then, we are a bit low, but not by a large amount.

Now let us consider model behavior under learning. We show, in Table 6, a sampling of output of four different values for the updating parameter, $k$, at three different dates: five years after the beginning of the intervention, ten years after and twenty. The top panel summarizes the results using the model-consistent expectations version of the model ${ }^{17}$ while the bottom panel shows the results for the limited-information version. In both cases, it is the Taylor rule that governs monetary policy. The numbers in the table are basis points of change in absolute terms so that "1.00" means that full convergence has been achieved.

16. The fact that disinflation under full credibility with limited information is less costly than under full information will be surprising to those who recall the opposite results from the new classical literature of the 1970s and early 1980s. Here, however, the errors in expectations along the transition path evidently aid the process of disinflation. The precise source of this phenomenon, which is fairly robust to the choice of policy rule, is under investigation.

17. For the model-consistent expectations simulations under learning we use a linearized version of the model. This avoids a great many numerical problems and saves time at only a small cost since the model is close to linear. 
Table 6

FRB/US Model Disinflation Experiments

Model-Consistent Expectations versus VAR-based Expectations

Learning from Fed Funds Rate Surprises with the Taylor Rule

\begin{tabular}{|c|c|c|c|c|c|c|c|c|c|}
\hline \multirow{3}{*}{$\begin{array}{c}\text { learning rate } \\
(\%)\end{array}$} & \multicolumn{9}{|c|}{ Panel (a) Model Consistent Expectations (at selected years) } \\
\hline & \multicolumn{3}{|c|}{ expected target } & \multicolumn{3}{|c|}{ inflation } & \multicolumn{3}{|c|}{ sacrifice ratio } \\
\hline & 5 & 10 & 20 & 5 & 10 & 20 & 5 & 10 & 20 \\
\hline 2.5 & 0.38 & 0.63 & 0.86 & 0.42 & 0.74 & 0.95 & 2.0 & 2.6 & 3.2 \\
\hline 5 & 0.62 & 0.86 & 0.98 & 0.56 & 0.88 & 0.99 & 1.7 & 2.2 & 2.5 \\
\hline 10 & 0.86 & 0.98 & 1.00 & 0.72 & 0.96 & 0.97 & 1.5 & 1.9 & 2.0 \\
\hline 25 & 0.99 & 1.00 & 1.00 & 0.83 & 0.95 & 0.95 & 1.5 & 1.7 & 1.7 \\
\hline credible & 1.00 & 1.00 & 1.00 & 0.96 & 1.01 & 1.00 & 1.4 & 1.7 & 1.6 \\
\hline \multicolumn{10}{|c|}{ Panel (b) VAR-based expectations (at selected years) } \\
\hline learning rate & \multicolumn{3}{|c|}{ expected target } & \multicolumn{3}{|c|}{ inflation } & \multicolumn{3}{|c|}{ sacrifice ratio } \\
\hline$(\%)$ & 5 & 10 & 20 & 5 & 10 & 20 & 5 & 10 & 20 \\
\hline 2.5 & 0.07 & 0.14 & 0.30 & 0.32 & 0.40 & 0.51 & 2.6 & 5.1 & 8.6 \\
\hline 5 & 0.14 & 0.27 & 0.50 & 0.37 & 0.49 & 0.65 & 2.3 & 4.2 & 6.3 \\
\hline 10 & 0.25 & 0.47 & 0.77 & 0.44 & 0.63 & 0.84 & 2.0 & 3.2 & 4.3 \\
\hline 25 & 0.48 & 0.80 & 1.03 & 0.60 & 0.87 & 1.02 & 1.5 & 2.3 & 2.7 \\
\hline credible & 1.00 & 1.00 & 1.00 & 1.03 & 1.01 & 0.99 & 1.0 & 1.4 & 1.4 \\
\hline
\end{tabular}

Notes: Sacrifices are measured in terms of undiscounted cumulative decrease in annualized employment, in percentage points, divided by the change in inflation relative to the baseline at each date.

Whereas in Figure 2 we saw remarkable similarity, here we see interesting differences. The bottom line of each panel in the table shows the results for the simulations shown in Figure 2. Let us begin by contrasting the sacrifice ratios for those simulations, with the sacrifice ratios for the slowest rates of learning, 2.5 per cent per quarter. In the case of model-consistent expectations, the difference in sacrifice ratios from full credibility and very slow learning rate is only twofold: a sacrifice ratio of 3.2 after 20 years when agents learn slowly, versus 1.6 when they immediately believe a disinflation is forthcoming. In the limited-information case, however, the differ- 
ences are more marked; the slow-learning case has a sacrifice ratio over six times larger than the fully credible case.

One reason for this difference is that in the absence of credibility, monetary policy in the limited-information case must do more of its work through the standard Keynesian channel of reducing aggregate demand. We see this in the fact that actual inflation runs consistently ahead of the perceived target. A large part of the reason for this is that longer-term bond rates, which are modeled using the expectations theorem of the term structure, do not move in advance of movements of aggregate demand in the absence of credibility. This implies higher sacrifice ratios, and a front-loading of the costs of disinflation. Slow learning implies slow adjustment of inflation in the limited-information case; even at the remarkably fast rate of 25 percent per quarter, the expected target is only 80 percent of the way to the authority's objective after ten years.

In the model-consistent case, the actual inflation rate and the expected target inflation rate are much closer together. Interestingly, only at the slowest speed of learning does the expect target rate of inflation lag behind actual inflation after five years. And the economy gets a lot of benefit for a relatively small amount of learning; a ten percent learning rate produces sacrifice ratios that are quite close to the full-credibility figures, and drives the expected target to inside of 15 percent of the way to its destination within five years.

There is a school of thought that suggests that a 'cold shower' disinflation will be less costly in terms of forgone employment by eliciting a discrete jump in the perceived target inflation rate at the outset of the exercise. Running against this argument is the standard Keynesian notion that if price and wage rigidities are structural, then policy that fails to take into consideration the pace at which they can adjust will end up creating more and longer lasting unemployment than is necessary for the task. This issue is examined in Table 7 where we compare the performance of the Post-1970s policy rule with the Taylor rule. In order to give expectations the best possible chance to jump rapidly to a new, lower level we use model-consistent expectations. The upper panel of the table is identical to Table 6.

Table 7 shows that indeed the harsh medicine of the Post-1970s rule delivers a more rapid decline in the perceived target rate of inflation than the Taylor rule, for all rates of learning. However this speedier disinflation is at the cost of larger accumulated employment losses. Since even the fully credible disinflation is more costly than with the Taylor rule, evidently the Post-1970s rule operates against binding constraints in terms of adjustment costs. In essence, the Post-1970s rule cannot produce federal funds rate surprises at any faster a rate than it produces excess supply. $^{18}$ 
Table 7

FRB/US Model Disinflation Experiments

Taylor Rule versus the Post-1970s Rule under Model Consistent Expectations Learning from Fed Funds Rate Surprises

\begin{tabular}{|c|c|c|c|c|c|c|c|c|c|}
\hline \multirow{3}{*}{$\begin{array}{c}\text { learning rate } \\
(\%)\end{array}$} & \multicolumn{7}{|c|}{ Panel (a) Taylor Rule (at selected years) } & & \\
\hline & \multicolumn{3}{|c|}{ expected target } & \multicolumn{3}{|c|}{ inflation } & \multicolumn{3}{|c|}{ sacrifice ratio } \\
\hline & 5 & 10 & 20 & 5 & 10 & 20 & 5 & 10 & 20 \\
\hline 2.5 & 0.38 & 0.63 & 0.86 & 0.42 & 0.74 & 0.95 & 2.0 & 2.6 & 3.2 \\
\hline 5 & 0.62 & 0.86 & 0.98 & 0.56 & 0.88 & 0.99 & 1.7 & 2.2 & 2.5 \\
\hline 10 & 0.86 & 0.98 & 1.00 & 0.72 & 0.96 & 0.97 & 1.5 & 1.9 & 2.0 \\
\hline 25 & 0.99 & 1.00 & 1.00 & 0.83 & 0.95 & 0.95 & 1.5 & 1.7 & 1.7 \\
\hline credible & 1.00 & 1.00 & 1.00 & 0.96 & 1.01 & 1.00 & 1.4 & 1.7 & 1.6 \\
\hline \multicolumn{10}{|c|}{ Panel (b) Post-1970s Rule (at selected years) } \\
\hline learning rate & \multicolumn{3}{|c|}{ expected target } & \multicolumn{3}{|c|}{ inflation } & \multicolumn{3}{|c|}{ sacrifice ratio } \\
\hline$(\%)$ & 5 & 10 & 20 & 5 & 10 & 20 & 5 & 10 & 20 \\
\hline 2.5 & 0.63 & 0.78 & 0.92 & 0.80 & 0.90 & 0.97 & 2.9 & 4.5 & 5.7 \\
\hline 5 & 0.86 & 0.95 & 0.99 & 0.94 & 1.00 & 0.99 & 2.4 & 3.6 & 4.1 \\
\hline 10 & 0.98 & 1.00 & 1.00 & 1.01 & 1.00 & 0.99 & 2.1 & 3.0 & 3.1 \\
\hline 25 & 1.00 & 1.01 & 1.00 & 1.00 & 1.00 & 0.99 & 2.0 & 2.5 & 2.5 \\
\hline credible & 1.00 & 1.00 & 1.00 & 0.98 & 1.00 & 0.98 & 1.9 & 2.2 & 2.2 \\
\hline
\end{tabular}

Notes: Sacrifices are measured in terms of undiscounted cumulative changes in the annualized employment rate divided by the change in inflation relative to the baseline as of the date indicated.

There are, however, other characterizations of monetary policy that may support cold shower disinflations. For example, if one were to model central bankers choosing, unobserved by private agents, high or low inflation regimes based on their 'conservativeness', then it might be possible for conservative central bankers to signal their intentions by choosing a tougher course of

18. One way in which the monetary authority could bring about a larger initial surprise and reduce the perceived target more rapidly would be to add a large one-time discretionary jump in the federal funds rate at the start of the disinflation. This may be what some people mean when they speak of 'cold shower' disinflations. While this would bring inflation to its target more quickly, the cost in forgone employment would be higher in the long run, at least for linear learning rules of the class used here. 
disinflation than a less conservative central banker would choose to mimic. This kind of mechanism could produce the kind of nonlinear or discrete adjustments in expectations that would be necessary to justify cold shower disinflations.

We can now compare, in broad terms, the sacrifice ratios of Table 6 and Table 7 with our stylized facts from Table 1 . If we take as before, 2 to $2-1 / 2$ as benchmark numbers for sacrifice ratios, we observe that one needs either slow learning with otherwise rational expectations, or fast learning with limited information to reconcile the model with the historical sacrifice ratio. A calibration of a learning rule, using survey data, to the Volcker disinflation can yield a learning rate anywhere between two percent and about 15 percent, depending on the precise specification of the rule and on the particular survey. These observations suggest it is hard to reconcile the VARexpectations version of the model under smooth learning rules at about a five-percent rate--about the middle of this range--with the benchmark sacrifice ratio. One possibility is that learning has been more discrete than our constant-gain specification permits. This notion has some intuitive appeal since, although the errors are steadily diminishing, in the Taylor rule simulations with limited information, agents learning at a rate of five percent per quarter are still making errors of the same sign even twenty years after the initiation of the disinflation. It might be reasonable to model agents engaged in 'second-derivative' learning--where they learn proportionately higher rate when they witness larger errors than small. ${ }^{19}$

Now let us repeat the exercise of Table 7 for the limited-information case in Table 8. The top panel of Table 8 is identical to the bottom panel of Table 6. From Table 8 we can see that a better case can be made for a more aggressive disinflation when expectations are not model consistent, at least as they are modeled in the limited-information version of FRB/US. For all cases except for the fully credible disinflation, the sacrifice ratio is the same or lower as for the Taylor rule. Moreover, the Post-1970s rule delivers disinflation more rapidly than does the Taylor rule. This is because the aggressive Post-1970s rule, given the VAR for expectations, produces larger surprises in the federal funds rate in the short run. More important, based on the VAR, agents forecast that these surprises will persist for longer than turns out to be the case.

19. We must also acknowledge the fact that many, if not most, of the sacrifice ratios in Table 1 are not computed to correspond with so well-defined an experiment as the ones we have considered for this paper. In the case of Ball (1994) for example, sacrifice ratios were computed between periods when inflation was constant for an arbitrary period of time on the accelerationist logic that if inflation is constant, the output gap must be closed (or equivalently, the unemployment rate is at the NAIRU). In a stochastic economy, however, a zero gap is neither necessary nor sufficient for inflation to be constant for relatively short periods of time. Ball's methodology will therefore have a tendency to overstate the number and understate the length of episodes. Lastly, the learning rates take as given the survey estimates of inflation expectations. It is quite possible that the available surveys are a poor proxy of longer-term expected inflation as we conceive of it here. 


\section{Table 8}

FRB/US Model Disinflation Experiments

Taylor Rule versus the Post-1970s Rule under VAR-based Expectations

Learning from Fed Funds Rate Surprises

\begin{tabular}{|c|c|c|c|c|c|c|c|c|c|}
\hline \multicolumn{10}{|c|}{ Panel (a) Taylor Rule (at selected years) } \\
\hline learning rate & \multicolumn{3}{|c|}{ expected target } & \multicolumn{3}{|c|}{ inflation } & \multicolumn{3}{|c|}{ sacrifice ratio } \\
\hline$(\%)$ & 5 & 10 & 20 & 5 & 10 & 20 & 5 & 10 & 20 \\
\hline 2.5 & 0.07 & 0.14 & 0.30 & 0.32 & 0.40 & 0.51 & 2.6 & 5.1 & 8.6 \\
\hline 5 & 0.14 & 0.27 & 0.50 & 0.37 & 0.49 & 0.65 & 2.3 & 4.2 & 6.3 \\
\hline 10 & 0.25 & 0.47 & 0.77 & 0.44 & 0.63 & 0.84 & 2.0 & 3.2 & 4.3 \\
\hline 25 & 0.48 & 0.80 & 1.03 & 0.60 & 0.87 & 1.02 & 1.5 & 2.3 & 2.7 \\
\hline credible & 1.00 & 1.00 & 1.00 & 1.03 & 1.01 & 0.99 & 1.0 & 1.4 & 1.4 \\
\hline \multicolumn{10}{|c|}{ Panel (b) Post-1970s Rule (at selected years) } \\
\hline learning rate & \multicolumn{3}{|c|}{ expected target } & \multicolumn{3}{|c|}{ inflation } & \multicolumn{3}{|c|}{ sacrifice ratio } \\
\hline$(\%)$ & 5 & 10 & 20 & 5 & 10 & 20 & 5 & 10 & 20 \\
\hline 2.5 & 0.14 & 0.25 & 0.46 & 0.60 & 0.54 & 0.68 & 2.0 & 5.2 & 8.0 \\
\hline 5 & 0.26 & 0.45 & 0.72 & 0.70 & 0.66 & 0.84 & 1.8 & 4.2 & 5.7 \\
\hline 10 & 0.46 & 0.72 & 0.94 & 0.85 & 0.81 & 0.97 & 1.6 & 3.2 & 3.9 \\
\hline 25 & 0.72 & 1.08 & 1.00 & 1.13 & 1.08 & 1.00 & 1.4 & 2.0 & 2.4 \\
\hline credible & 1.00 & 1.00 & 1.00 & 1.07 & 0.98 & 1.00 & 1.3 & 1.5 & 1.4 \\
\hline
\end{tabular}

Notes: Sacrifices are measured in terms of undiscounted cumulative decreases in annualized employment divided by the change in inflation relative to the baseline as of the date indicated.

This leads them to the expect lower future levels of output and inflation than would be warranted under model consistent expectations. Thus it is often the case, with the post-1970s rule, that the effect of policy misperception on the numerator of the sacrifice ratio is greater than that on the denominator.

This is the key for low-cost disinflation under limited information: the monetary authority must produce surprises to agents' expectations--the larger and more consistent the better--but the surprises must be expected to persist longer than they in fact do. In this sense, the best set of a priori beliefs for the private sector to have are those that are consistent with small movements in fed- 
eral funds rate settings to begin with, but that are expected to grow and persist for some time. It is in this way that agents' extrapolation of surprises do some of the work for the authority, mitigating to some extent the need for active policy measures in the future. The core VAR equation for the federal funds rate, shown in Table 3, is well suited for this since the small impact coefficients on inflation combined with very large coefficients on lagged endogenous variables means agents expect long-lived and hump-shaped responses to federal funds rate surprises. ${ }^{20}$ The Post-1970s rule, by contrast, has larger impact coefficients and somewhat smaller coefficients on the lagged endogenous variables. A policy maker using the Post-1970s rule will tend, therefore, to deliver large shocks to the federal funds rate, as perceived by the private sector, that are expected to persist for longer than they do.

By contrast, the relatively mild response of the Taylor rule, combined with its absence of dynamics, tends to produce expectations of lower inflation than in fact materializes. The economy experiences lower output without all the disinflationary benefits. Figure 3 gives an idea of how this works; it shows a comparison of learning at 10 percent per quarter with the Taylor rule and the Post-1970s rule, both simulated under conditions of limited information. Expected target inflation under the Taylor rule begins to decline rapidly, but then retrenches as agents come to realize that policy is not as aggressive as had been expected. This means that the sign of the surprise to the federal funds rate has changed. By contrast, the aggressive action of the Post-1970s rule produces an early decline in inflation without, initially at least, a prior or coincident large decrease in employment. This is the direct effect of federal funds rate surprises on expected target inflation. Then, the monetary authority operating under the Post-1970s rule, confirms its aggressiveness through its willingness to tolerate higher unemployment than it does under the Taylor rule. However, as noted above and shown by the dashed lines of the north-west panel of Figure 3, this has a greater effect on expected target inflation and on actual inflation than it does on foregone employment. The path of expected target inflation under the Post-1970s rule undulates as it declines over time but never retrenches.

The last line of both panels of Table 8 confirms the old story about the gradualism versus cold shower as a special case: if agents have rational expectations, the monetary authority has credibility, and there are intrinsic costs to adjusting prices: it is always better in terms of the undiscounted employment or output cost to disinflate gradually.

20. When we speak of "impact coefficients" we mean all coefficients on inflation in the core VAR or in the policy rules, not just the coefficient on the contemporaneous variable. Similarly, when we speak of "lagged endogenous variables" we mean all lags of the federal funds rate. 
Figure 3

FRB/US Disinflation Experiments (deviations from base case)

Taylor Rule versus Post -1970s Rule under Limited Information

Learning from Fed Funds Rate Surprises at 10 percent rate

Inflation and Expected Target Inflation

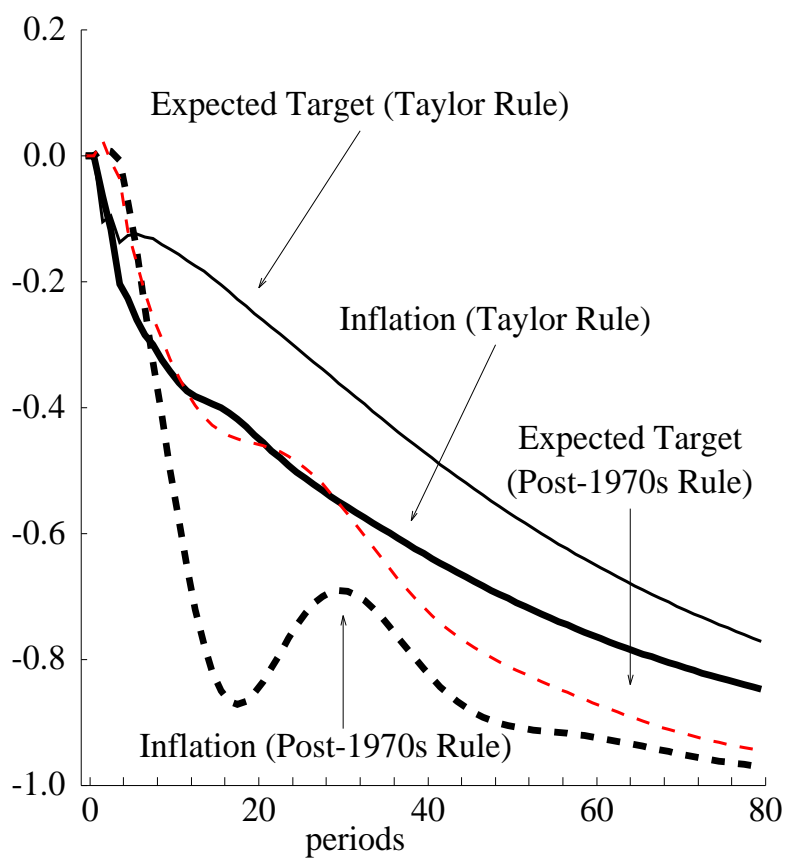

Nominal Federal Funds Rate

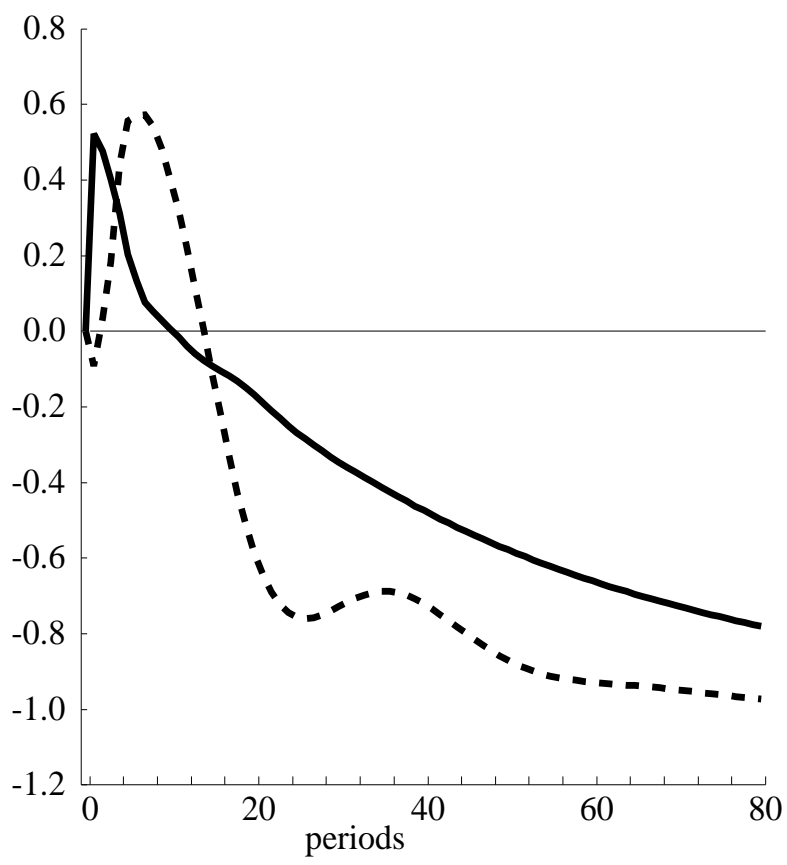

Unemployment Rate

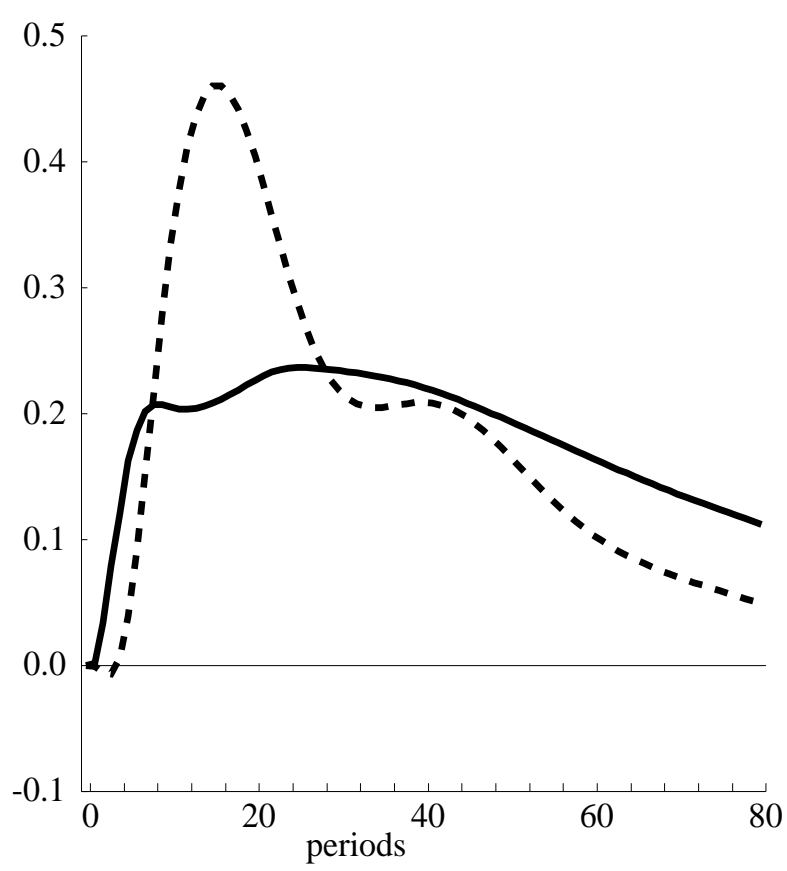

5-year Government Bond Rate

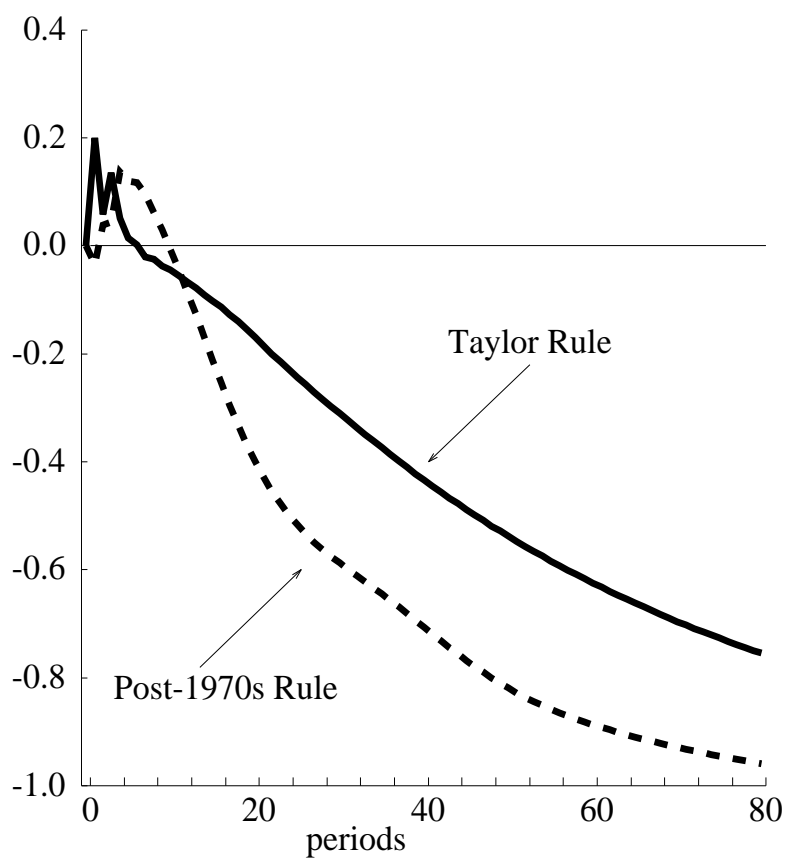


For completeness, we show in Figure 4 the 10-percent learning case with model-consistent expectations. Given the limited scope for perceptual errors to play a role in these scenarios, the paths of the variables tend to be quite smooth. With the obvious exception of the unemployment gap and, to a lesser extent, the inflation rates, the two rules produce broadly similar behavior. There are, however, important differences between Figure 4 and the full-credibility model-consistent simulation in Figure 2. The most obvious difference is that business cycle dynamics take considerably longer to play out when agents must learn the intentions of the Fed. In fact, the peak response of unemployment under the Taylor rule with learning (solid line, north-east panel of Figure 4) is about the same as it is under full credibility (Figure 2): unemployment simply persists substantially more when agents must learn the objectives of monetary policy. Another difference is that while the nominal federal funds rate and the government bond rate fall instantaneously in the full credibility case, they rise, initially, when agents must learn. Expected future short-term interest rates are consistently overpredicted when agents must learn, which means that long bond rates are also overpredicted.

\section{Concluding Remarks}

This paper has examined the issue of expectations formation and learning on the costs of disinflation, using the Federal Reserve Board's new quarterly macroeconometric model, FRB/US. Our goals in this regard were three-fold. First, we sought to demonstrate some of the properties and capabilities of the model in terms of its ability to handle meaningful policy analysis experiments that ought to be expected to engender shifts in private-sector expectations, as per Lucas (1976). In particular, we hoped to show how learning rules could be introduced into the basic model structure. Second, we wanted to examine the implications of alternative policy rules for disinflation. Our goal in this instance was demonstrative rather than exhaustive with the analysis focusing on the aggressiveness of (linear) rules, not on the fine points of specification. Finally, we wanted to examine whether the model's structure and estimation could be reconciled with measures of the historical sacrifice ratio using plausible parameters in a simple learning rule. 


\section{Figure 4}

FRB/US Disinflation Experiments (deviations from base case)

Taylor Rule versus Post -1970s Rule under Model-Consistent Expectations

Learning from Fed Funds Rate Surprises at 10 percent rate

Inflation and Expected Target

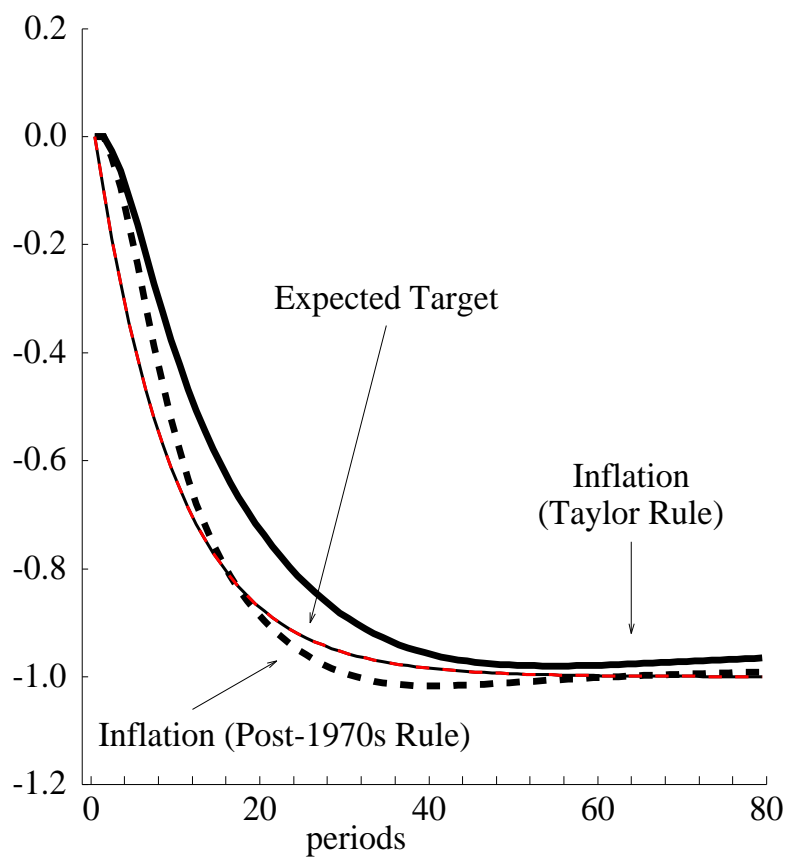

Nominal Federal Funds Rate

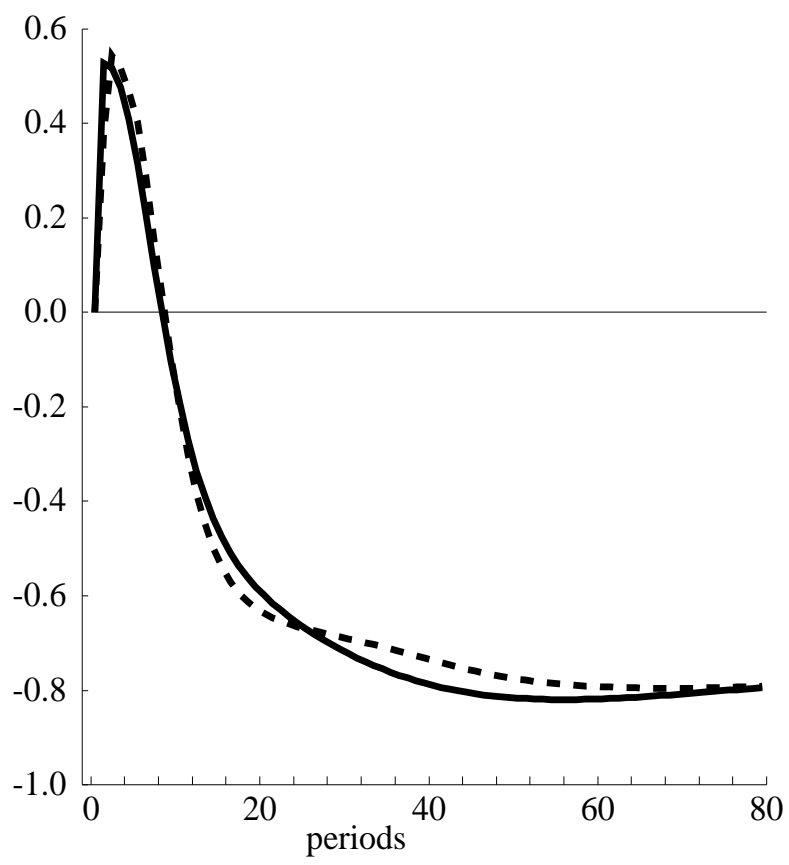

Unemployment Rate

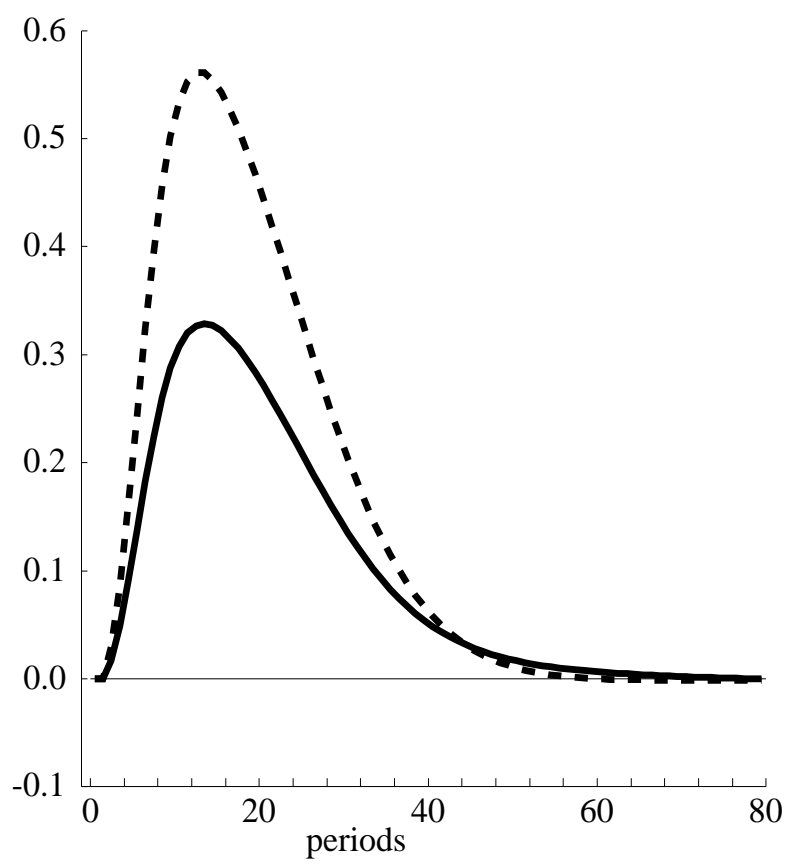

5-year Government Bond Rate

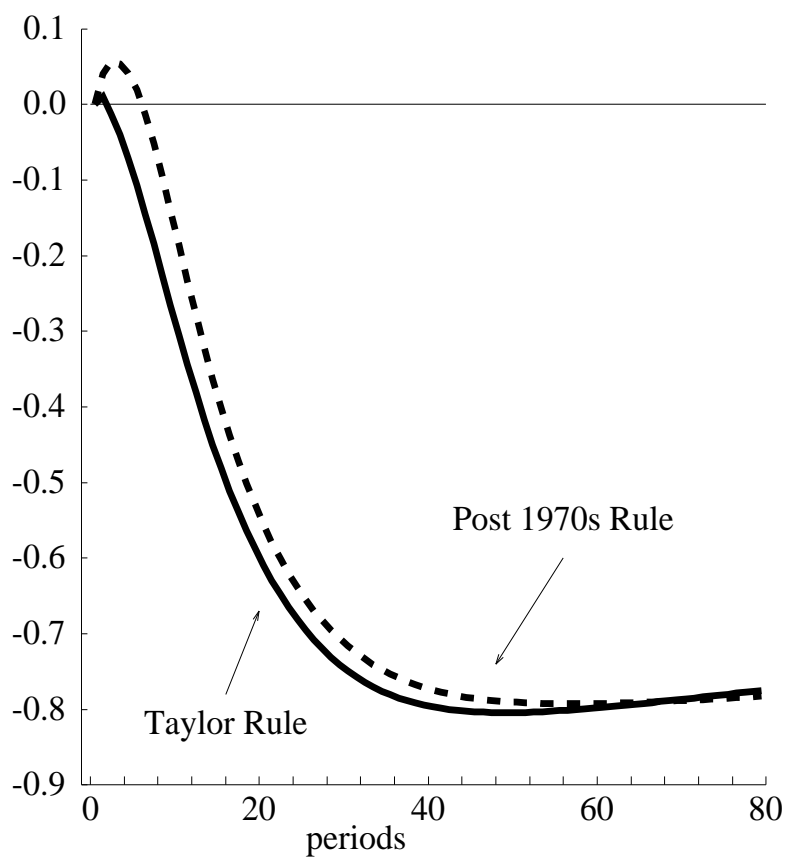


On our first two objectives, we would argue that the model acquitted itself well. The model is able to simulate disinflations with learning at a host of different rates and using expectations that are either model-consistent or based on limited information as represented by a smallscale VAR. Moreover, we were able to demonstrate a case for both sides in the debate on gradualism versus cold shower in disinflation.

Ironically, while proponents of cold shower policies often couch their claims in the parlance of rational expectations models, the case for cold shower disinflations in the FRB/US depiction of the U.S. economy rests on exploiting the sluggishness of private expectations, lulled into a sense of complacency by average history policy. A measure of caution is advisable in considering this result, however, as not all cases of the Post-1970s rule under limited information better the Taylor rule. More importantly, the superiority of adopting a rule like the Post-1970s rule over the Taylor rule at the outset of a disinflation will depend on the prior expectations of agents. These cannot be observed directly and proxies, whether econometric or from surveys, are subject to measurement error. Nevertheless, the result is intriguing. By contrast when given what many would believe is the best possible circumstances to show gains from rapid disinflation -- model consistent expectations and fast learning -- our results show dominance for gradualism. Taken together, and given the myriad of other plausible learning rules that one might consider -- particularly nonlinear or higher-derivative rules -- one would have to conclude that the old debate of gradualism versus cold shower remains an open question.

On our final objective, our results were more mixed. If one takes for granted that the "correct" sacrifice ratio if a number of the order of 2 to $2-1 / 2$, measured, say, after ten years, then there are only a few combinations of expectations formation methods and rules that produce the acceptable number. An unaggressive rule like the Taylor rule will do the job, for all learning rates under model consistent expectations, and for fast learning under limited information. There are only a few combinations using the Post-1970s rule that can produce a sacrifice ratio of less than 3 at 10 years or longer. There is irony in this result too since the Post-1970s rule is, as the name suggests, fitted to the Volcker disinflation, the least costly disinflation in recent history. It is possible, how-

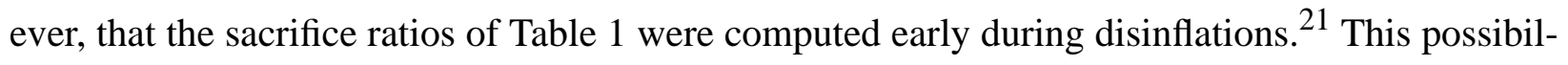
ity gives one solace since, the bottom panel of Table 8 , for example, shows sacrifice ratios of 2 or less at five years, and disinflations that are between 60 and 107 percent complete.

21. As noted previously, the Ball (1994) methodology for computing sacrifice ratios tends to shorten the length of a disinflationary episode. 


\section{References}

Anderson, Gary and George Moore (1985) "A Linear Algebraic Procedure for Solving Linear Perfect Foresight Models” 17,Economics Letters, pp. 247-252.

Ball, Laurence M. (1994) "What Determines the Sacrifice Ratio?" in N. G. Mankiw (ed.) Monetary Policy (Chicago: University of Chicago Press), pp. 155-182.

Blackburn, Keith and Michael Christensen (1985) "Monetary Policy and Credibility: a critical review" 23,Journal of Economic Literature, 2 (June).

Blanchard, Olivier J. (1985) "Debt, Deficits and Finite Lives" 93,Journal of Political Economy,2 pp. 223-247.

Blinder, Allan S. (1987) Hard heads, soft hearts: Tough-minded economics for a just society (Reading, Mass.: Addison-Wesley)

Brayton, Flint and Peter Tinsley (1995) "Polynomial Generalization of Dynamic Frictions in Structural Macro Models” FRB staff working paper, June 1995.

Brayton, Flint and Peter Tinsley (eds.) (1996) “A Guide to FRB/US: A Macroeconometric Model of the United States” Finance and Economics Discussion Series no. 1996-42 (October).

Buiter, Willem H. and Ian Jewitt (1981) "Staggered Wage Setting with Real Wage Relativities: Variations on a Theme of Taylor" 49,The Manchester School 211-228.

Bullard, James B. (1991) "Learning, Rational Expectations and Policy: A Summary of Recent Research“ Federal Reserve Bank of St. Louis Review (January/February), pp. 50-60.

Calvo, Guillermo A. (1983) "Staggered Contracts in a Utility-maximizing Framework" 12,Journal of Monetary Economics (September), pp. 383-398.

Chadha, Benkim; Paul R. Masson and Guy Meredith (1992) "Models of Disinflation and the Costs of Disinflation” 39,IMF Staff Papers,2 (June) pp. 395-431.

Fair, Ray C. and John B. Taylor (1983) "Solution and Maximum Likelihood Estimation of Dynamic Nonlinear Rational Expectations Models” 51,Econometrica,4 (July), pp. 11691185.

Fuhrer, Jeffrey C. (1994) “Optimal Monetary Policy and the Sacrifice Ratio" in Jeffrey C. Fuhrer (ed.) Goals, Guidelines, and Constraints Facing Monetary Policymakers proceedings of a conferences held at the Federal Reserve Bank of Boston, June 1994. (Boston: Federal Reserve Bank of Boston), pp. 43-69.

Fuhrer, Jeff and George Moore (1995) “Inflation Persistence” 110,Quarterly Journal of Economics,1 (February), pp. 127-159. 
Goodhart, Charles A.E. and José Viñals (1994) "Strategy and Tactics of Monetary Policy: Examples form Europe and the Antipodes" in J.C. Fuhrer (ed.) Goals, Guidelines, and Constraints Facing Monetary Policymakers proceedings of a conferences held at the Federal Reserve Bank of Boston, June 1994. (Boston: Federal Reserve Bank of Boston), pp. 139-187.

Gordon, Robert J. and Stephen R. King (1982) “The Output Cost of Disinflation in Traditional and Vector Autoregressive Models" Brookings Papers on Economic Activity, 1 pp. $205-$ 242.

Hansen, Lars P. and Thomas J. Sargent (1980) "Formulating and Estimating Dynamic Linear Rational Expectations Models" 2,Journal of Economic Dynamics and Control,1 (February), pp. 7-46

Kozicki, Sharon and Peter Tinsley (1996) "Moving Endpoints and the Internal Consistency of Agents' Ex Ante Forecasts" FEDS series working paper no. 96-47, Board of Governors of the Federal Reserve System (November).

Kozicki, Sharon; Dave Reifschneider and Peter Tinsley (1995) "The Behavior of Long-Term Interest Rates in the FRB/US Model" unpublished manuscript. Macroeconomic and Quantitative Studies Section, Board of Governors of the Federal Reserve (December).

Lucas, Robert E. (1972) "Expectations and the Neutrality of Money" 4,Journal of Economic Theory,2 (April), pp. 103-124.

Lucas, Robert E. (1976) "Econometric Policy Evaluation: A Critique" Carnegie-Rochester Conference Series on Public Policy,1 (Spring) pp. 19-46.

Mankiw, N. Gregory (1991) Macroeconomics (New York: Worth).

Mussa, Michael (1981) "Sticky Prices and Disequilibrium Adjustment in a Rational Model on the Inflationary Process” 71,American Economic Review,6 (December), pp. 1020-1027.

Nickell, Stephen (1986) "Error Correction, Partial Adjustment and All That: An Expository Note" 47,Oxford Bulletin of Economics and Statistics, 2 pp. 199-129.

Okun, Arthur M. (1978) "Efficient Disinflationary Policies” 68,American Economic Review,2 (May), pp. 348-352.

Rotemberg, Julio (1983) "Aggregate Implications of Fixed Costs of Adjusting Prices" 73,American Economic Review,3 (June) pp. 343-346.

Sargent, Thomas J. (1993) Bounded Rationality in Economics (Oxford: Clarendon).

Taylor, John B. (1980) “Aggregate Dynamics and Staggered Contracts” 88,Journal of Political Economy,1 (February), pp. 1-24.

Taylor, John B. (1993) "Discretion versus Policy Rules in Practice” 39, Carnegie-Rochester Conference Series on Public Policy,2 (Autumn), pp. 195-214. 
Taylor, John B. (1994) “The Inflation/Output Variability Tradeoff Revisited” in Jeffrey C. Fuhrer (ed.) Goals, Guidelines, and Constraints Facing Monetary Policymakers proceedings of a conferences held at the Federal Reserve Bank of Boston, June 1994. (Boston: Federal Reserve Bank of Boston), pp. 21-38.

Tinsley, Peter (1970) “On Ramps, Turnpikes, and Distributed Lag Approximations of Optimal Intertemporal Adjustment” 8, Western Economic Journal,5 (December) pp. 397-411.

Tinsley, Peter (1993) "Fitting Both Data and Theories: Polynomial Adjustment Cost and ErrorCorrection Decision Rules" FEDS Working Paper 93-21 (June). 